\title{
Plummer-Vinson Syndrome: A Case Report
}

\author{
Gedam DS ${ }^{1}$, Mandliya $\mathrm{J}^{2}$, Verma $\mathbf{M}^{3}$
}

${ }^{1}$ Dr. D Sharad Gedam, Associate Professor, Department of Paediatrics, ²Dr Jagdish Mandliya, Associate Professor, Department of Paediatrics, ${ }^{3}$ Ms. Mamta Verma, Associate Professor, Department of Paediatric Nursing. All from R.D Gardi Medical College Ujjain, M.P., India.

Address for correspondence: Dr. D Sharad Gedan, E-mail: sharad.gedam@gmail.com

\begin{abstract}
Plummer-Vinson also known as sideropenic dysphagia is a disease that is characterized by classical triad of iron deficiency anemia, dysphagia and esophageal web. It is known to mostly affect white female mainly, but cases have been reported from other ethnic group in the literature. Treatment is very promising especially when it is not associated with carcinoma.
\end{abstract}

\section{Introduction}

Plummer-Vinson Syndrome (PVS) was first described by Patterson and Kelly in 1919 ${ }^{1}$. It consists of the triad of dysphagia, iron deficiency anemia and upper esophageal web(s). Along with it, it also consists of atrophic oral mucosa, cracks or fissure at the corners of the mouth along with painful tongue, koilonychia or nails that are brittle and break easily ${ }^{2,3}$. Dysphagia is usually progressive over years, and limited to solids. Most of the patients affected are middle aged women and it is very rare in childhood ${ }^{2,3}$.

\section{Case report}

We report such a case occurring in an adolescent boy of 13-years age. He presented with pain abdomen and progressive difficulty in swallowing especially solid food since the last one month.

He had poor nutritional status and history of pica. Physical examination was normal except for pallor. The weight was in the $25^{\text {th }}$ percentile for age and height was at the $50^{\text {th }}$ percentile.

The laboratory evaluation revealed an iron deficiency anemia with a hemoglobin level of $8.5 \mathrm{~g} /$ $\mathrm{dl}$, mean cell volume $52.5 \mathrm{fl}$ (80.7-95.5), mean cell hemoglobin $13.7 \mathrm{pg}$ (27.2-33.5), MCHC 26.1 g/dl. Serum iron $12.8 \mu \mathrm{g} / \mathrm{dl}(59-158)$, total iron binding capacity 422.8 $\mu \mathrm{g} / \mathrm{dl}(245-450)$,

Radiological examination by barium swallow showed the presence of smoothly outlined circular constriction noted at origin of cervical oesophagus most likely due to a web.

The boy was treated with endoscopic balloon dilation and iron supplementation. At the end of one month of iron therapy, fatigue and dysphagia disappeared and the patient began to gain weight. After one month hemoglobin and MCV level showed an improvement to $11 \mathrm{~g} / \mathrm{dl}$ and $70 \mathrm{fl}$, respectively. He remains in good general condition without any dysphagic complaints even after six months of treatment.

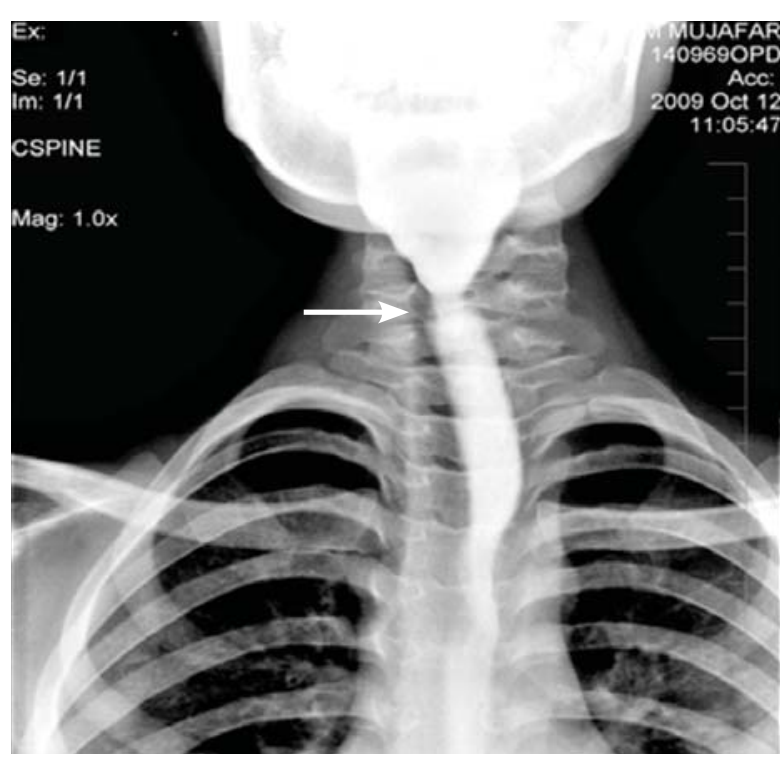

Fig 1: Barium Swallow showing the indentations (arrows) of the proximal esophagus indicating webs. 


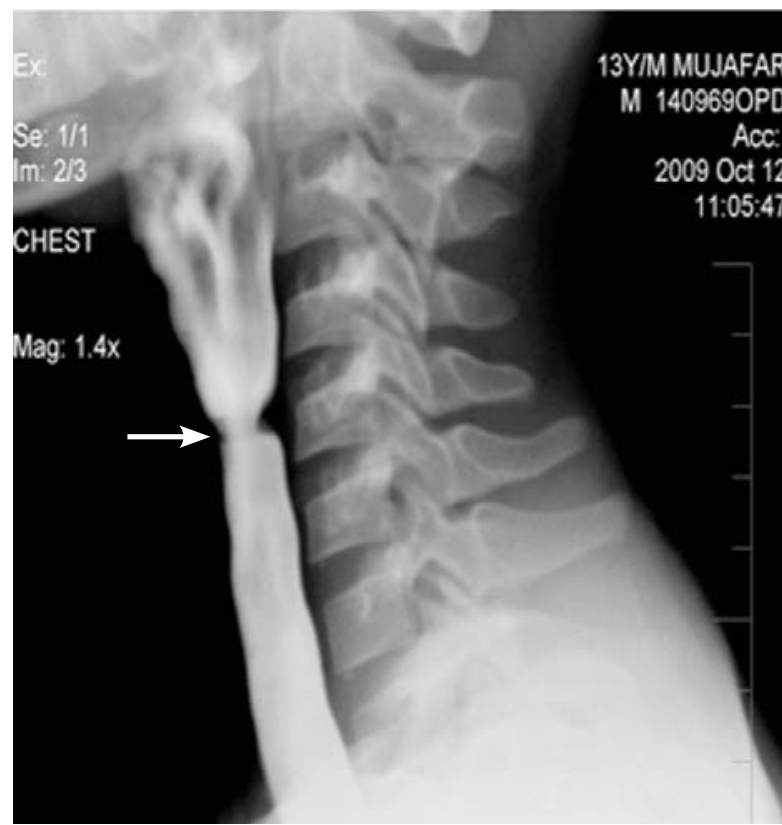

Fig.2. Barium Swallow showing the indentations (arrows) of the proximal esophagus indicating webs (oblique view).

\section{Discussion}

The main clinical features of PVS are upper esophageal web(s), dysphagia and iron deficiency anemia ${ }^{1}$. Most of the patients are middle-aged women and it is thought to occur via blood loss from menstruation and pregnancy ${ }^{2,3}$. To our knowledge only 10 cases of this syndrome has been reported in English literature in children and adolescents ${ }^{4-8,17}$. Symptoms resulting from anemia such as pallor, fatigue and weakness may dominate the clinical picture, in our case patient had suffered from dysphagia and pain abdomen.

The pathogenesis of this syndrome is not exactly understood but the most probable mechanism is iron deficiency ${ }^{9}$. The other factors, such as genetic predisposition, malnutrition and autoimmunity have not been proven to play an exact role in the pathogenesis of the syndrome, although celiac disease, thyroid disease and rheumatoid arthritis have been reported with PVS ${ }^{1,10,11}$. Whatever the source of the iron deficiency, the theory is based on the rapid loss of iron-dependent enzymes. Reduction of these enzymes may cause mucosal degenerations, atrophic changes and web formation and may even lead to cancer of the upper gastrointestinal tract $^{8,12}$. The previous studies showed that iron deficiency decreased the contraction amplitude of the esophageal muscle resulting in motility impairment ${ }^{13,14,15}$. Although iron deficiency anemia is not uncommon in our country, we find very few cases of Plumer-Vinson Syndrome in children, reported from India. Exact number of reported cases in children is not available. In contrast to adults ${ }^{2,16}$ Plummer-Vinson syndrome is rare, especially in childhood. We think that any child presenting with dysphagia and iron deficiency symptoms should be investigated for PVS. The prognosis is good but due to the possibility of malignant transformation, regular follow-up is necessary.

\section{References}

1. Novacek G. Plummer-Vinson syndrome. Orphanet J Rare Dis 2006;1:36.

2. Demirci F, Savas MC, Kepkep N, et al. PlummerVinson syndrome and dilation therapy: a report of two cases. Turk J Gastroenterol 2005;16:224-27.

3. Atmatzidis K, Papaziogas B, Pavlidis T, Mirelis $\mathrm{CH}$, Papaziogas T. Plummer-Vinson syndrome. Dis Esophagus 2003;16:154-57.

4. Crawfurd MD, Jacobs A, Murphy B, Peters DK.Paterson-Kelly syndrome in adolescence: a report of five cases. Br Med J 1965;1:693-95.

5. Seitz ML, Sabatino D. Plummer-Vinson syndrome in an adolescent. J Adolesc Health 1991;12:279-81.

6. Anthony R, Sood S, Strachan DR, Fenwick JD. A case of Plummer-Vinson syndrome in childhood. J Pediatr Surg 1999;34:1570-572.

7. Mansell NJ, Jani P, Bailey CM. Plummer-Vinson syndrome - a rare presentation in a child. $J$ Laryngol Otol 1999;113:475-76.

8. Lopez Rodriguez MJ, Robledo Andres P, Amarilla Jimenez A, Roncero Maillo M, Lopez Lafuente A, Arroyo Carrera I. Sideropenic dysphagia in an adolescent. $J$ Pediatr Gastroenterol Nutr 2002;34:87-90.

9. Okamura H, Tsutsumi S, Inaki S, Mori T. Esophageal web in Plummer-Vinson syndrome. Laryngoscope 1988;98:994-98.

10. Sood A, Midha V, Sood N, Bansal M. Paterson Kelly syndrome in celiac disease. J Assoc Physicians India 2005;53:991-92.

11. Medrano M. Dysphagia in a patient with rheumatoid arthritis and iron deficiency anemia. Med Gen Med 2002;28:10.

12. Anderson SR, Sinacori JT. Plummer-Vinson syndrome heralded by postcricoid carcinoma. Am J Otolaryngol 2007;28:22-24.

13. Dantas RO, Villanova MG. Esophageal motility impairment in Plummer-Vinson syndrome. 
Correction by iron treatment. Dig Dis $\mathrm{Sci}$ 1993;38:968-71.

14. Dantas RO. Iron deficiency and dysphagia. Am J Gastroentero1 1999;94:3072-73.

15. Miranda AL, Dantas RO. Esophageal contractions and oropharyngeal and esophageal transits in patients with iron deficiency anemia. $A m \mathrm{~J}$ Gastroenterol 2003;98:1000-1004.
16. Uygur-Bayramicli O, Tuncer K, Dolapcioglu C. Plummer- Vinson syndrome presenting with an esophageal stricture. J Clin Gastroenterol 1999;29:291-92.

17. Dinler G, Tander B, Kalaycı AG, Rızalar R .PlummerVinson syndrome in a 15-year-old boy. Turkish $\mathrm{J}$ Pediatr 2009;51:384-86.

\section{How to cite this article?}

Gedam DS, Mandliya J, Verma M. Plummer-Vinson Syndrome- A Case Report. J Nepal Paediatr Soc 2011;31(3):254-256. 